\title{
Selection of Key Component Vendor from the Aspects of Capability, Productivity, and Reliability
}

\author{
Vincent F. Yu, ${ }^{1}$ Catherine W. Kuo, ${ }^{2}$ and Luu Quoc Dat ${ }^{1,3}$ \\ ${ }^{1}$ Department of Industrial Management, National Taiwan University of Science and Technology, No. 43, Sec. 4, Keelung Road, \\ Taipei 10607, Taiwan \\ ${ }^{2}$ Graduate Institute of Management, National Taiwan University of Science and Technology, No. 43, Sec. 4, Keelung Road, \\ Taipei 10607, Taiwan \\ ${ }^{3}$ Faculty of Development Economics, University of Economics and Business, Vietnam National University, \\ No. 144 Xuan Thuy Road, Cau Giay District, Hanoi 10000, Vietnam
}

Correspondence should be addressed to Catherine W. Kuo; ckworldwide66@gmail.com

Received 16 March 2014; Revised 2 June 2014; Accepted 8 June 2014; Published 2 July 2014

Academic Editor: W. Y. Szeto

Copyright (c) 2014 Vincent F. Yu et al. This is an open access article distributed under the Creative Commons Attribution License, which permits unrestricted use, distribution, and reproduction in any medium, provided the original work is properly cited.

\begin{abstract}
In a technology-driven industry, the appropriate vendors/suppliers can effectively contribute to cobusiness development profits. Key component vendors help dynamically drive solution design firms to achieve strong performances, especially when an integrated circuit (IC) component that has technical know-how specifications dominates an electronic solution design. This paper presents a systematic framework to examine the decision process for the selection of wireless fidelity (Wi-Fi) IC vendor alternatives from the business ecosystem aspect in order to review the importance of buyer-supplier synergistic effects. We implement the fuzzy analytic hierarchy process technique which incorporates a vendor's capability, productivity, and reliability characteristics into a hierarchical structure and deploys decision experts' judgments along with vague data analysis to solve a real-world problem faced by a leading company specialized in the research and design of wireless networking solutions. The findings indicate the Taiwanese local vendor is the top priority for alternatives selection, and the results contribute significant values to the design firm's operation management.
\end{abstract}

\section{Introduction}

In the information, communication, and technology (ICT) industry where technological specifications are phased into an electronic device, the issues of suppliers' competitive advantages are measured more in depth than the terms and conditions of price/cost, product/service quality, or delivery. A key component vendor, as part of business supply chain cells, is devoted to technological skills so as to achieve market driven requirements. When a Wi-Fi IC component adopts technological specifications, deploys a solution design-in technique, dominates $1 / 2$ of a main board cost, and even shares $1 / 3$ of the bill-of-material (BOM) cost in one wireless networking device, the decision to purchase or replace a key component is more than just a bargaining power negotiation conducted by a single procurement department.

Several research studies have released results on the impacts of vendors' (suppliers') characteristics under different industrial viewpoints so as to examine and measure the selection of vendor/supplier alternatives. Appropriate vendors/suppliers can effectively contribute to cobusiness development profits, especially in technology-driven industries. Close buyer-supplier relationships can share business information and technology development trends [1]. During the product development stage, the decision to integrate product architecture with a supply chain design is significantly important for industries [2]. Thus, matching new product feature developments with the choice of suppliers can impact firm performance, for example, when solutions contain new electronic components and new process techniques in the automotive industry [3]. The stable delivery of goods and technology ability are the top two criteria for selecting suppliers in the electronics industry [4]. Product quality is one distinct examination attribute of suppliers when outsourcing technological specification products that are applied during a procurement decision process analysis for railway parts [5]. Buyers' operations can be severely impacted due to suppliers' 
reliability to deliver on time in this outsourced supply chain management era [6]. Even appropriate vendor alternatives are implemented when evaluating the quality of product durability in steel component selection [7]. For a notebook manufacturer, the lowest unit cost of an outsourced TFT-LCD part is not the first priority for an appropriate supplier [8], whereas for product cost effectiveness, quality stability, and on-time delivery concerns, a garment manufacturing firm's top management evaluates appropriate suppliers through its $\mathrm{R} \& \mathrm{D}$, marketing, and purchasing departments' evaluation feedback [9].

This paper measures and analyzes one Wi-Fi IC vendor's alternatives by looking at the tactics within the enterprise's organizational culture as well as operation management characteristics in the wireless networking communications industry. Following a review of knowledgeable product design engineers, project managers' judgments, and salespersons' feedback, we find some significant impact factors classified as follows: (i) sensitivity to market competition, the abilities of up-to-date advanced technology, and the skills of financial management through vendors' competitiveness capabilities; (ii) the fact that product price justifies flexibility, production output arrangement, and inventory planning management of vendors' performance; (iii) the confidence in components' quality and delivery as well as the risk management of the vendors.

Fuzzy analytic hierarchy process, which was first proposed by [10], has become one of the most widely used tools for multiple criteria decision making (MCDM). The literature has proposed numerous fuzzy analytic hierarchy process (AHP) methods to solve various types of problems [11-19]. Among the existing AHP approaches, the extent analysis method proposed by [12] is a commonly used approach that is highly cited and has wide applications. The AHP methodology is utilized to demonstrate a hierarchical structure and to examine the weights of the decision elements reviewed and evaluated by experts, while the proposed fuzzy AHP technique can effectively consider the vagueness of decision makers' opinions on the ranking of alternative suppliers. This study applies the fuzzy AHP technique proposed by [12] to incorporate a vendor's capability, productivity, and reliability characteristics into a hierarchical structure to deploy decision experts' judgment and also implements vague data analysis.

The remainder of the paper is organized as follows. Section 2 presents the research background along with the related literature. Section 3 proposes the fuzzy analytic hierarchy process methodology. Section 4 applies the fuzzy AHP methodology to the selection of Wi-Fi IC component vendor alternatives. Finally, Section 5 draws conclusions and discussions.

\section{Literature Review}

Maximizing profits through cost-expenditure minimization is the fundamental philosophy of a corporate operation management strategy, but reviewing the related influential elements is an essential and critical process. For a more global industrial environment, the issue on firms' competition advantage always stresses their operation and the contribution from suppliers' expertise and how it affects the firms' success. Through firms' synergistic effects, suppliers' core competence can be integrated into new product design and business development with the benefits being cost reduction and time efficiency. Reference [20] highlights the importance of high-tech business success through the synergistic resolution of strategic network effects, while [21] examines the contribution of IT resource synergy to organizational performance and how competitiveness is substantial and flourishing. In a technology-driven industry and market environment, the outsourced solutions from knowledgeable suppliers present systematic impacts related to the development of products/projects. Reference [22] indicates that a strong relationship with suppliers can result in new product development outsourcing being controlled quite well in technology-intensive markets. Under a complete business development ecosystem, buyers (customers/users) and suppliers (solution/service providers) are interdependent in a value-added supply chain network. Reference [23] shows that the partner selection of direct suppliers is one of the important success factors for the core business of a mobile business ecosystem. Reference [24] analyzes the effect of early supplier involvement on project team's effectiveness. Through new project/product developers' and contributors' coordination in their supply chain team involvement, continual customer value creation can be achieved. Reference [25] points out that a demand and supply integration mechanism plays a tremendous role due to intrateams' knowledge integration and management. Reference [26] provides insights of coordination between new product development and supply chain management for value creation.

Several research studies look at some factors affecting vendor selection criterion as analyzed by the fuzzy set theory and AHP approaches. Reference [13] indicates that steel quality, cost, and delivery issues for a metal manufacturing company are the major measurement criteria of supplier selection implemented on electronic marketplaces. Reference [17] identifies and measures suppliers' technical ability variable for a washing machine case research on supplier selection. Reference [19] concludes that vendors' financial position, quality, and delivery are the top three factors for a multicriteria supplier segmentation evaluation applied to a case analysis in the food industry. Reference [27] addresses capabilities of suppliers' financial, technical, and production factors that affect a health product firm's decision on supplier evaluation and selection. Furthermore, the risks from geographical location and political and economical stability impact supplier selection [28] and outsourcing risk management due to economic environmental crises [29], while the criteria of risk in inventory control management [30] are prime factors across suppliers and buyers. Reference [31] proposes a fuzzy logic approach to supplier evaluation for development.

In the electronics industry, special material vendors/suppliers mostly play the key role in devoting their capabilities, productivities, and reliabilities to support the final product/solution providers during the new product design or new project development phases. Reference [18] notes that the 
TABLE 1: Characteristics released on the vendor/supplier selection references.

\begin{tabular}{lc}
\hline Characteristics & References \\
\hline Delivery & {$[1,4,6-9,13,17,19,27,28]$} \\
Cost/price & {$[1,4,7-9,13,17-19,27-29,32]$} \\
Quality & {$[1,4,5,7,9,13,17-19,27-29,32,33]$} \\
Technology & {$[1,4,7,17,27,33]$} \\
Risk & {$[1,18,28]$} \\
Production & {$[4,7,17,27]$} \\
Finance & {$[4,5,7,17,19,32]$} \\
Inventory & {$[6,30]$} \\
\hline
\end{tabular}

cost criterion is the first priority of concern, followed by quality, service, and risk, for a Taiwanese digital consumer manufacturer to select its global suppliers. Reference [32] addresses an evaluation process of supplier selection and firmly identifies technique capability as well as design and development ability as the two major influential elements in professional technology for one electronic manufacturer. In the initial stage of new product development, [33] indicates that quality reliability and technological capability are important subcriteria factors adopted for plastic injection vendor selection by a personal digital assistant (PDA) developer. Table 1 reviews the characteristics in the vendor/supplier selection. Reference [34] uses a qualitative, embedded singlecase strategy in shipbuilding industry to explore the importance of supplier capabilities in one shipyard and examines how consistently the shipyard and its 20 suppliers assess the capabilities of the suppliers.

\section{Fuzzy Analytic Hierarchy Process Methodology}

This study adopts the extent analysis method proposed by [12] due to its computational simplicity. The extent analysis method is briefly discussed as follows.

Let $X=\left\{x_{1}, x_{2}, \ldots, x_{n}\right\}$ be an object set and let $U=$ $\left\{u_{1}, u_{2}, \ldots, u_{m}\right\}$ be a goal set. According to [12], each object is taken and an extent analysis for each goal $\left(g_{i}\right)$ is performed, respectively. Therefore, the $m$ extent analysis values for each object are obtained as $M_{g_{i}}^{1}, M_{g_{i}}^{2}, \ldots, M_{g_{i}}^{n}, i=1,2, \ldots, n$, where $M_{g_{i}}^{j}(j=1,2, \ldots, m)$ are triangular fuzzy numbers (TFNs).

Assume that $M_{g_{i}}^{j}$ are the values of extent analysis of the $i$ th object for $m$ goals. The value of fuzzy synthetic extent $S_{i}$ is defined as

$$
S_{i}=\sum_{j=1}^{m} M_{g_{i}}^{j} \otimes\left[\sum_{i=1}^{n} \sum_{j=1}^{m} M_{g_{i}}^{j}\right]^{-1}
$$

where $\sum_{j=1}^{m} M_{g_{i}}^{j}=\left(\sum_{j=1}^{m} l_{j}, \sum_{j=1}^{m} m_{j}, \sum_{j=1}^{m} u_{j},\right), j=1,2, \ldots$, $m, i=1,2, \ldots, n$.

Let $M_{1}=\left(l_{1}, m_{1}, u_{1}\right)$ and $M_{2}=\left(l_{2}, m_{2}, u_{2}\right)$ be two TFNs, whereby the degree of possibility of $M_{1} \geq M_{2}$ is defined as follows:

$$
V\left(M_{1} \geq M_{2}\right)=\sup _{x \geq y}\left[\min \left(\mu_{M_{1}}(x), \mu_{M_{2}}(x)\right)\right] .
$$

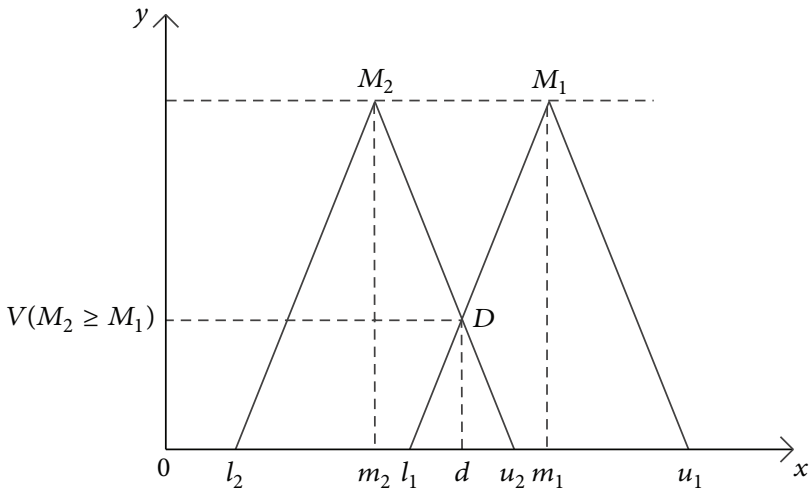

FIgURE 1: The comparison of two fuzzy numbers.

The membership degree of possibility is expressed as

$$
\begin{aligned}
V\left(M_{1} \geq M_{2}\right)= & \operatorname{hgt}\left(M_{1} \cap M_{2}\right)=\mu_{M_{2}}(d) \\
= & \begin{cases}1 & \text { if } m_{1} \geq m_{2} \\
0 & \text { if } l_{1} \geq u_{2} \\
\frac{l_{1}-u_{2}}{\left(m_{2}-u_{2}\right)-\left(m_{1}-l_{1}\right)} & \text { otherwise, }\end{cases}
\end{aligned}
$$

where $d$ is the ordinate of the highest intersection point of two membership functions $\mu_{M_{1}}(x)$ and $\mu_{M_{2}}(x)$, as shown in Figure 1.

The degree of possibility for a convex fuzzy number to be greater than $k$ convex fuzzy numbers is defined as

$$
\begin{array}{r}
V\left(M \geq M_{1}, M_{2}, \ldots, M_{k}\right)=\min V\left(M \geq M_{i}\right), \\
i=1,2, \ldots, k .
\end{array}
$$

The weight vector is given by

$$
W^{\prime}=\left(d^{\prime}\left(A_{1}\right), d^{\prime}\left(A_{2}\right), \ldots, d^{\prime}\left(A_{n}\right)\right)^{T},
$$

where

$$
\begin{aligned}
A_{i}(i=1,2, \ldots, n), \quad d^{\prime}\left(A_{i}\right) & =\min V\left(S_{i} \geq S_{k}\right), \\
k & =1,2, \ldots, n ; k \neq i .
\end{aligned}
$$

Via normalization, we obtain the weight vectors as

$$
W=\left(d\left(A_{1}\right), d\left(A_{2}\right), \ldots, d\left(A_{n}\right)\right)^{T},
$$

where $W$ is a nonfuzzy number.

In this present case, Chang's method [12] is applied to solve a vendor selection and evaluation problem. We adopt a "Likert scale" of fuzzy numbers starting from 1 to 9 to transform the linguistic values into TFNs, as shown in Table 2.

\section{The Empirical Case Analysis}

To a wireless networking technology-driven firm, the intrarelationship management with its vendors is conducted 
TABLE 2: Triangular fuzzy conversation scale [11].

\begin{tabular}{llcc}
\hline & Linguistic values & $\begin{array}{c}\text { Triangular fuzzy } \\
\text { numbers }\end{array}$ & $\begin{array}{c}\text { Reciprocal triangular } \\
\text { fuzzy scale }\end{array}$ \\
\hline$(1)$ & Unimportant (U) & $(1,1,1)$ & $(1,1,1)$ \\
$(2)$ & Between U and SL & $(1,2,3)$ & $(1 / 3,1 / 2,1)$ \\
$(3)$ & Slightly important (SL) & $(2,3,4)$ & $(1 / 4,1 / 3,1 / 2)$ \\
$(4)$ & Between SL and MI & $(3,4,5)$ & $(1 / 5,1 / 4,1 / 3)$ \\
$(5)$ & Moderately important (MI) & $(4,5,6)$ & $(1 / 6,1 / 5,1 / 4)$ \\
$(6)$ & Between MI and SI & $(5,6,7)$ & $(1 / 7,1 / 6,1 / 5)$ \\
$(7)$ & Seriously important (SI) & $(6,7,8)$ & $(1 / 8,1 / 7,1 / 6)$ \\
$(8)$ & Between SI and VSI & $(7,8,9)$ & $(1 / 9,1 / 8,1 / 7)$ \\
$(9)$ & Very seriously important (VSI) & $(1 / 9,1 / 9,1 / 8)$ \\
\hline
\end{tabular}

TABLE 3: Fuzzy AHP analysis of key Wi-Fi component IC vendors' evaluation and selection.

\begin{tabular}{|c|c|c|c|}
\hline Criteria & Definition & Subcriteria & Definition \\
\hline \multirow{3}{*}{ Capability $\left(C_{1}\right)$} & \multirow{3}{*}{$\begin{array}{l}\text { Expertise and } \\
\text { experiences related to } \\
\text { competitiveness }\end{array}$} & Market sensitivity $^{*}\left(\mathrm{MS}-C_{11}\right)$ & $\begin{array}{l}\text { To meet market trends and customer } \\
\text { requirements }\end{array}$ \\
\hline & & Technology availability $\left(\right.$ TA- $\left.C_{12}\right)$ & $\begin{array}{l}\text { To achieve up-to-date technological } \\
\text { specification design }\end{array}$ \\
\hline & & Financial stability $\left(\mathrm{FS}-\mathrm{C}_{13}\right.$ ) & To manage financial operation \\
\hline \multirow{3}{*}{ Productivity $\left(C_{2}\right)$} & \multirow{3}{*}{$\begin{array}{l}\text { Flexibilities and } \\
\text { arrangement }\end{array}$} & Price policy $\left(\mathrm{PP}-\mathrm{C}_{21}\right)$ & To adjust cost/pricing offerings \\
\hline & & Production capacity $\left(\mathrm{PC}-\mathrm{C}_{22}\right)$ & To fulfill just-in-time demand \\
\hline & & Inventory strategy $^{* *}\left(\right.$ IS- $\left.C_{23}\right)$ & $\begin{array}{l}\text { To control materials and allocation of } \\
\text { finished goods }\end{array}$ \\
\hline \multirow{3}{*}{ Reliability $\left(C_{3}\right)$} & \multirow{3}{*}{$\begin{array}{l}\text { Accuracy and } \\
\text { commitments on } \\
\text { management }\end{array}$} & Product quality $\left(\mathrm{PQ}-\mathrm{C}_{31}\right)$ & To ensure product performance \\
\hline & & On-time delivery (TD- $C_{32}$ ) & To arrange delivery schedules \\
\hline & & Risk management $\left(\mathrm{RM}-\mathrm{C}_{33}\right)$ & To manage risk factors \\
\hline
\end{tabular}

Note: ${ }^{*}$ key subcriteria for Wi-Fi IC supplier selection; ${ }^{* *}$ must subcriteria to judge Wi-Fi IC suppliers' performance and management.

through global business development so as to overcome the limitations of technological knowledge. To become a qualified key component vendor to fulfill system designers' requirements, alternative candidates should be fully and systematically evaluated. This research presents a measurement analysis on a fifty-employee Taiwanese R\&D design firm with a very good track record for five consecutive years in wireless networking solution design. The critical decision for this firm is to select an appropriate value-added Wi-Fi IC vendor from two choices: (a) Vendor A is a well-known world-class firm that specializes in networking, computing, and mobile solutions design for home and enterprise users, including applications utilized on digital homes, notebooks, tablets, mobile phones, mobile routers, and so forth; (b) Vendor B is a publicly traded IC design company in Taiwan with a broader range of high-tech product applications, including solutions for implementation on computer peripherals, communication networks, and multimedia. Based on a questionnaire survey feedback from 5 managers (2 electronic engineers, 2 project managers, and one account manager) of each vendor and 7 managers ( 2 project managers, 2 procurement managers, 1 engineer for firmware, 1 electronic engineer, and one sales account) of the case study's design firm received in October 2013, we apply a methodology to measure the weights of three criteria and nine subcriteria, respectively, and examine the weights of the nine subcriteria versus alternatives from the final score of fuzzy AHP analysis. Table 3 and Figure 2 define the criteria and subcriteria used to evaluate and select Wi-Fi IC vendors.

Based on criteria and subcriteria defined in Table 3 and (1)-(7), we are able to calculate the importance weights of the criteria and subcriteria as well as the weights of alternatives versus the subcriteria in Tables 4-6.

We are now able to obtain the final score of each alternative as Table 7.

The data indicates that the vendor's productivity $\left(C_{2}: 0.55\right)$ is a relatively greater concern versus the other two criteria (see Table 4). On the weights of the subcriteria, financial stability $\left(C_{13}: 1.0\right)$ is the most important factor under the decision choice on the capability term, and inventory stability $\left(C_{23}: 0.54\right)$ and production capability $\left(C_{22}\right.$ : 0.46) impact the greatest upon the productivity issue, while risk management $\left(C_{33}: 0.52\right)$ and on-time delivery $\left(C_{32}: 0.48\right)$ hold critical weights under the reliability criterion (see Table 5). For the weights of the two alternatives versus the nine subcriteria, respectively, the Fuzzy AHP approach analysis chooses Vendor $\mathrm{B}\left(A_{2}: 0.724\right.$ versus $\left.A_{1}: 0.276\right)$ as the top priority for alternatives selection (see Tables 6 and 7).

\section{Conclusions and Discussions}

The selection of key component vendor alternatives involves multiple issues that can be systematically examined through 
TABLE 4: The importance weights of the criteria.

\begin{tabular}{lcccccccccc}
\hline Criteria & \multicolumn{3}{c}{$C_{1}$} & & $C_{2}$ & & $C_{3}$ & \\
\hline$C_{1}$ & 1.00 & 1.00 & 1.00 & 0.30 & 0.38 & 0.48 & 0.54 & 0.72 & 0.87 \\
$C_{2}$ & 2.08 & 2.62 & 3.32 & 1.00 & 1.00 & 1.00 & 0.55 & 0.76 & 1.00 & 0.55 \\
$C_{3}$ & 1.15 & 1.39 & 1.84 & 1.00 & 1.32 & 1.80 & 1.00 & 1.00 & 1.00 & 0.45 \\
\hline
\end{tabular}

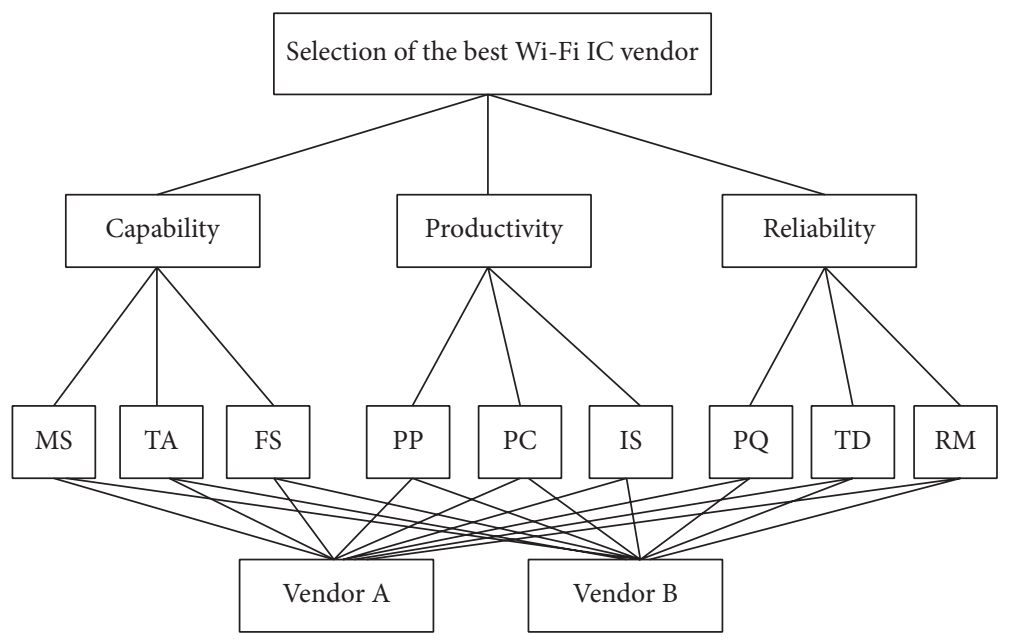

FIGURE 2: Hierarchy of Wi-Fi component IC vendors' evaluation and selection problem.

TABLE 5: The importance weights of the subcriteria.

\begin{tabular}{|c|c|c|c|c|c|c|c|c|c|c|}
\hline Subcriteria & & $C_{11}$ & & & $C_{12}$ & & & $C_{13}$ & & $W_{c}$ \\
\hline$C_{11}$ & 1.00 & 1.00 & 1.00 & 0.96 & 1.19 & 1.38 & 0.33 & 0.45 & 0.57 & 0 \\
\hline$C_{12}$ & 0.72 & 0.84 & 1.04 & 1.00 & 1.00 & 1.00 & 0.24 & 0.31 & 0.40 & 0 \\
\hline$C_{13}$ & 1.76 & 2.24 & 3.00 & 2.47 & 3.24 & 4.24 & 1.00 & 1.00 & 1.00 & 1 \\
\hline Subcrite & & $C_{21}$ & & & $C_{22}$ & & & $C_{23}$ & & $W_{c}$ \\
\hline$C_{21}$ & 1.00 & 1.00 & 1.00 & 0.30 & 0.40 & 0.51 & 0.22 & 0.28 & 0.37 & 0 \\
\hline$C_{22}$ & 1.95 & 2.49 & 3.31 & 1.00 & 1.00 & 1.00 & 0.29 & 0.39 & 0.47 & 0.46 \\
\hline$C_{23}$ & 2.73 & 3.56 & 4.47 & 2.12 & 2.59 & 3.47 & 1.00 & 1.00 & 1.00 & 0.54 \\
\hline Subcr & & $C_{31}$ & & & $C_{32}$ & & & $C_{33}$ & & $W_{c}$ \\
\hline$C_{31}$ & 1.00 & 1.00 & 1.00 & 0.20 & 0.25 & 0.31 & 0.25 & 0.32 & 0.40 & 0 \\
\hline$C_{32}$ & 3.18 & 4.00 & 5.00 & 1.00 & 1.00 & 1.00 & 0.44 & 0.57 & 0.74 & 0.48 \\
\hline$C_{33}$ & 2.47 & 3.12 & 4.00 & 1.35 & 1.76 & 2.29 & 1.00 & 1.00 & 1.00 & 0.52 \\
\hline
\end{tabular}

teams' analysis under a multicriteria decision process. Targeting profit maximization, a Wi-Fi IC component supplier is driven by a product's bill-of-material (BOM) cost that results from the technological specifications/features that are phased in during a new product design stage. The insights from this empirical case study identify some important issues for the evaluation, measurement, and analysis actions during the decision process for key component vendor selection in technology-driven industries. Through the perspectives of synergistic effects and business ecosystems, we offer the following key results of our study for industries and academia. (i) The added value of the decision process on $\mathrm{Wi}$ Fi IC component vendors' selection encompasses technology know-how, the main IC that makes up the main cost of the solution main board, and the BOM cost performance. (ii) The blueprint of the examination factors focuses on
TABLE 6: The weights of alternatives versus the subcriteria.

\begin{tabular}{|c|c|c|c|c|c|c|c|}
\hline$W C_{11}$ & & $A_{1}$ & & & $A_{2}$ & & $W_{c}$ \\
\hline$A_{1}$ & 1.00 & 1.00 & 1.00 & 0.47 & 0.59 & 0.71 & 0 \\
\hline$A_{2}$ & 1.41 & 1.71 & 2.12 & 1.00 & 1.00 & 1.00 & 1 \\
\hline$W C_{12}$ & & $A_{1}$ & & & $A_{2}$ & & $W_{c}$ \\
\hline$A_{1}$ & 1.00 & 1.00 & 1.00 & 0.36 & 0.49 & 0.67 & 0 \\
\hline$A_{2}$ & 1.49 & 2.03 & 2.76 & 1.00 & 1.00 & 1.00 & 1 \\
\hline$W C_{13}$ & & $A_{1}$ & & & $A_{2}$ & & $W_{c}$ \\
\hline$A_{1}$ & 1.00 & 1.00 & 1.00 & 0.69 & 0.87 & 0.94 & 0.3 \\
\hline$A_{2}$ & 1.06 & 1.15 & 1.44 & 1.00 & 1.00 & 1.00 & 0.7 \\
\hline$W C_{21}$ & & $A_{1}$ & & & $A_{2}$ & & $W_{c}$ \\
\hline$A_{1}$ & 1.00 & 1.00 & 1.00 & 0.59 & 0.88 & 1.17 & 0.44 \\
\hline$A_{2}$ & 0.85 & 1.13 & 1.70 & 1.00 & 1.00 & 1.00 & 0.56 \\
\hline$W C_{22}$ & & $A_{1}$ & & & $A_{2}$ & & $W_{c}$ \\
\hline$A_{1}$ & 1.00 & 1.00 & 1.00 & 0.57 & 0.76 & 1.04 & 0.36 \\
\hline$A_{2}$ & 0.96 & 1.32 & 1.76 & 1.00 & 1.00 & 1.00 & 0.64 \\
\hline$W C_{23}$ & & $A_{1}$ & & & $A_{2}$ & & $W_{c}$ \\
\hline$A_{1}$ & 1.00 & 1.00 & 1.00 & 0.53 & 0.67 & 0.80 & 0 \\
\hline$A_{2}$ & 1.25 & 1.50 & 1.88 & 1.00 & 1.00 & 1.00 & 1 \\
\hline$W C_{31}$ & & $A_{1}$ & & & $A_{2}$ & & $W_{c}$ \\
\hline$A_{1}$ & 1.00 & 1.00 & 1.00 & 0.43 & 0.58 & 0.77 & 0.09 \\
\hline$A_{2}$ & 1.29 & 1.74 & 2.35 & 1.00 & 1.00 & 1.00 & 0.91 \\
\hline$W C_{32}$ & & $A_{1}$ & & & $A_{2}$ & & $W_{c}$ \\
\hline$A_{1}$ & 1.00 & 1.00 & 1.00 & 0.81 & 1.04 & 1.19 & 0.52 \\
\hline$A_{2}$ & 0.84 & 0.96 & 1.24 & 1.00 & 1.00 & 1.00 & 0.48 \\
\hline$W C_{33}$ & & $A_{1}$ & & & $A_{2}$ & & $W_{c}$ \\
\hline$A_{1}$ & 1.00 & 1.00 & 1.00 & 0.59 & 0.79 & 0.96 & 0.31 \\
\hline$A_{2}$ & 1.04 & 1.26 & 1.69 & 1.00 & 1.00 & 1.00 & 0.69 \\
\hline
\end{tabular}

the evaluation issues of (a) competitiveness capability, (b) productivity performance, and (c) management reliability. (iii) This study bridges gaps in previous research concerning 
TABLE 7: Final score of each alternative.

\begin{tabular}{ll}
\hline Alternative & Score \\
\hline$A_{1}$ & 0.276 \\
$A_{2}$ & 0.724 \\
\hline
\end{tabular}

market sensitivity on market trends and customer requirements. (iv) The key characteristics to look at during the vendor selection process come from vendors' viewpoints and the solution design firm's examination of the impacts from three criteria and nine subcriteria. (v) The results herein indicate that the strategic vendor evaluation analysis and report can be used as a reference by a firm's operation management when planning a strategy for resource allocation.

In an ICT technology-driven and customer-centric business ecosystem, firms need to structure a value chain mechanism through knowledge sharing network collaboration with key suppliers and customers. The scope and scale of future research should integrate cross-functional cooperation among teams to widely investigate the supply chain value in a global and dynamic context. Given these issues, we note the following. (1) Open innovation (OI), which involves a greater number of ideas, knowledge areas, and experiences contributed by external partners, is the key antecedent of strategic decisions made by firms. (2) Knowledge management (KM), which drives firms by sharing and deploying knowledge to organizations for objective achievement, is a multidisciplined theoretical approach suitable for industrial practitioners in research and analysis. Therefore, in order to build up different research criteria that can be integrated with quantitative measurement analysis theories, for future studies we propose research objectives on customer value creation and supply chain value through the use of multipurpose models.

\section{Conflict of Interests}

The authors declare that there is no conflict of interests regarding the publication of this paper.

\section{References}

[1] A. H. I. Lee, "A fuzzy supplier selection model with the consideration of benefits, opportunities, costs and risks," Expert Systems with Applications, vol. 36, no. 2, pp. 2879-2893, 2009.

[2] B. Nepal, L. Monplaisir, and O. Famuyiwa, "Matching product architecture with supply chain design," European Journal of Operational Research, vol. 216, no. 2, pp. 312-325, 2012.

[3] M. Pero, N. Abdelkafi, A. Sianesi, and T. Blecker, "A framework for the alignment of new product development and supply chains," Supply Chain Management, vol. 15, no. 2, pp. 115-128, 2010.

[4] B. Chang, C. Chang, and C. Wu, "Fuzzy DEMATEL method for developing supplier selection criteria," Expert Systems with Applications, vol. 38, no. 3, pp. 1850-1858, 2011.

[5] G. Bruno, E. Esposito, A. Genovese, and R. Passaro, "AHP-based approaches for supplier evaluation: problems and perspectives," Journal of Purchasing and Supply Management, vol. 18, no. 3, pp. 159-172, 2012.
[6] E. Elahi, "Outsourcing through competition: what is the best competition parameter?" International Journal of Production Economics, vol. 144, no. 1, pp. 370-382, 2013.

[7] M. Punniyamoorthy, P. Mathiyalagan, and P. Parthiban, "A strategic model using structural equation modeling and fuzzy logic in supplier selection," Expert Systems with Applications, vol. 38, no. 1, pp. 458-474, 2011.

[8] A. H. I. Lee, H. Kang, and C. Chang, "Fuzzy multiple goal programming applied to TFT-LCD supplier selection by downstream manufacturers," Expert Systems with Applications, vol. 36, no. 3, pp. 6318-6325, 2009.

[9] K. Shaw, R. Shankar, S. S. Yadav, and L. S. Thakur, "Supplier selection using fuzzy AHP and fuzzy multi-objective linear programming for developing low carbon supply chain," Expert Systems with Applications, vol. 39, no. 9, pp. 8182-8192, 2012.

[10] P. J. M. van Laarhoven and W. Pedrycz, "A fuzzy extension of Saaty's priority theory," Fuzzy Sets and Systems, vol. 11, no. 3, pp. 229-241, 1983.

[11] K. P. Anagnostopoulos, M. Gratziou, and A. P. Vavatsikos, "Using the fuzzy analytic hierarchy process for selecting wastewater facilities at prefectrure level," European Water, pp. 15-24, 2007.

[12] D. Chang, "Applications of the extent analysis method on fuzzy AHP," European Journal of Operational Research, vol. 95, no. 3, pp. 649-655, 1996.

[13] I. Chamodrakas, D. Batis, and D. Martakos, "Supplier selection in electronic marketplaces using satisficing and fuzzy AHP," Expert Systems with Applications, vol. 37, no. 1, pp. 490-498, 2010.

[14] C. A. Bana e Costa and J.-C. Vansnick, "A critical analysis of the eigenvalue method used to derive priorities in AHP," European Journal of Operational Research, vol. 187, no. 3, pp. 1422-1428, 2008.

[15] O. Çakir, "On the order of the preference intensities in fuzzy AHP," Computers and Industrial Engineering, vol. 54, no. 4, pp. 993-1005, 2008.

[16] L. Mikhailov, "Deriving priorities from fuzzy pairwise comparison judgements," Fuzzy Sets and Systems, vol. 134, no. 3, pp. 365385, 2003.

[17] O. Kilincci and S. A. Onal, "Fuzzy AHP approach for supplier selection in a washing machine company," Expert Systems with Applications, vol. 38, no. 8, pp. 9656-9664, 2011.

[18] C. Ku, C. Chang, and H. Ho, "Global supplier selection using fuzzy analytic hierarchy process and fuzzy goal programming," Quality and Quantity, vol. 44, no. 4, pp. 623-640, 2010.

[19] J. Rezaei and R. Ortt, "Multi-criteria supplier segmentation using a fuzzy preference relations based AHP," European Journal of Operational Research, vol. 225, no. 1, pp. 75-84, 2013.

[20] S. Shim and B. Lee, "Sustainable competitive advantage of a system goods innovator in a market with network effects and entry threats," Decision Support Systems, vol. 52, no. 2, pp. 308317, 2012.

[21] J.-L. Chen, “The synergistic effects of IT-enabled resources on organizational capabilities and firm performance," Information and Management, vol. 49, no. 3-4, pp. 142-150, 2012.

[22] N. Harmancioglu, "Portfolio of controls in outsourcing relationships for global new product development," Industrial Marketing Management, vol. 38, no. 4, pp. 394-403, 2009.

[23] J. Zhang and X. Liang, "Business ecosystem strategies of mobile network operators in the $3 \mathrm{G}$ era: the case of China Mobile," Telecommunications Policy, vol. 35, no. 2, pp. 156-171, 2011. 
[24] S. J. Wu and G. L. Ragatz, "Evaluating the total effect of early supplier involvement on project team effectiveness: collaboration and interaction," International Journal of Integrated Supply Management, vol. 5, no. 3, pp. 239-259, 2010.

[25] T. L. Esper, A. E. Ellinger, T. P. Stank, D. J. Flint, and M. Moon, "Demand and supply integration: a conceptual framework of value creation through knowledge management," Journal of the Academy of Marketing Science, vol. 38, no. 1, pp. 5-18, 2010.

[26] P. Hilletofth and D. Eriksson, "Coordinating new product development with supply chain management," Industrial Management and Data Systems, vol. 111, no. 2, pp. 264-281, 2011.

[27] J. Roshandel, S. S. Miri-Nargesi, and L. Hatami-Shirkouhi, "Evaluating and selecting the supplier in detergent production industry using hierarchical fuzzy TOPSIS," Applied Mathematical Modelling, vol. 37, no. 24, pp. 10170-10181, 2013.

[28] A. Zouggari and L. Benyoucef, "Simulation based fuzzy TOPSIS approach for group multi-criteria supplier selection problem," Engineering Applications of Artificial Intelligence, vol. 25, no. 3, pp. 507-519, 2012.

[29] D. Wu, D. D. Wu, Y. Zhang, and D. L. Olson, "Supply chain outsourcing risk using an integrated stochastic-fuzzy optimization approach," Information Sciences, vol. 235, pp. 242-258, 2013.

[30] Y. Kristianto, P. Helo, J. R. Jiao, and M. Sandhu, "Adaptive fuzzy vendor managed inventory control for mitigating the Bullwhip effect in supply chains," European Journal of Operational Research, vol. 216, no. 2, pp. 346-355, 2012.

[31] L. Osiro, F. R. Lima-Junior, and L. C. R. Carpinetti, "A fuzzy logic approach to supplier evaluation for development," International Journal of Production Economics, vol. 153, pp. 95-112, 2014.

[32] Y. Chen and R. Chao, "Supplier selection using consistent fuzzy preference relations," Expert Systems with Applications, vol. 39, no. 3, pp. 3233-3240, 2012.

[33] C.-Y. Shen and K.-T. Yu, "Enhancing the efficacy of supplier selection decision-making on the initial stage of new product development: a hybrid fuzzy approach considering the strategic and operational factors simultaneously," Expert Systems with Applications, vol. 36, no. 8, pp. 11271-11281, 2009.

[34] I. Ruuska, T. Ahola, M. Martinsuo, and T. Westerholm, "Supplier capabilities in large shipbuilding projects," International Journal of Project Management, vol. 31, no. 4, pp. 542-553, 2013. 


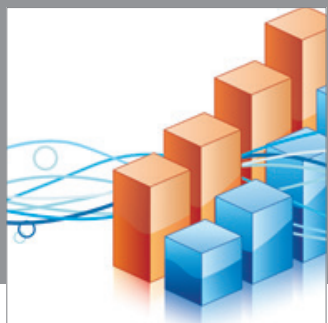

Advances in

Operations Research

mansans

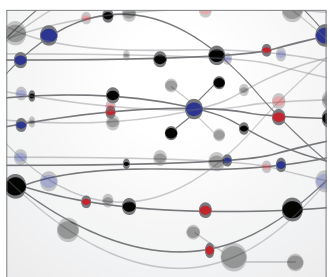

The Scientific World Journal
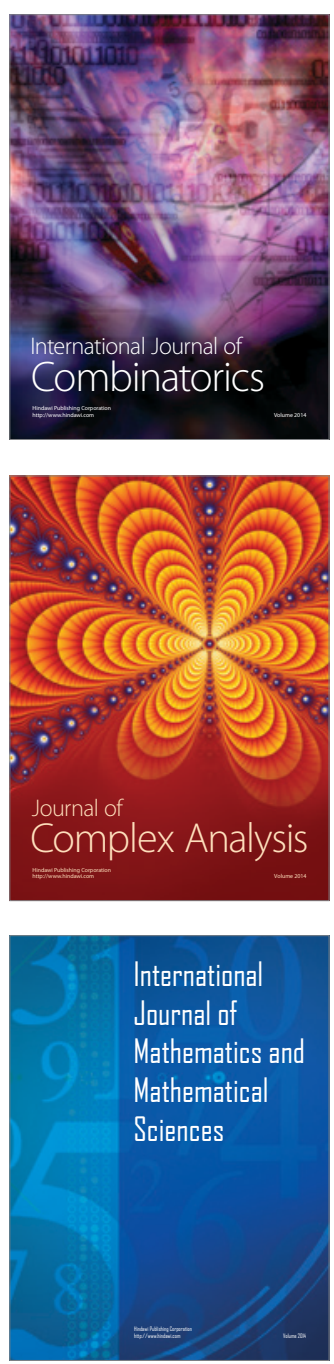
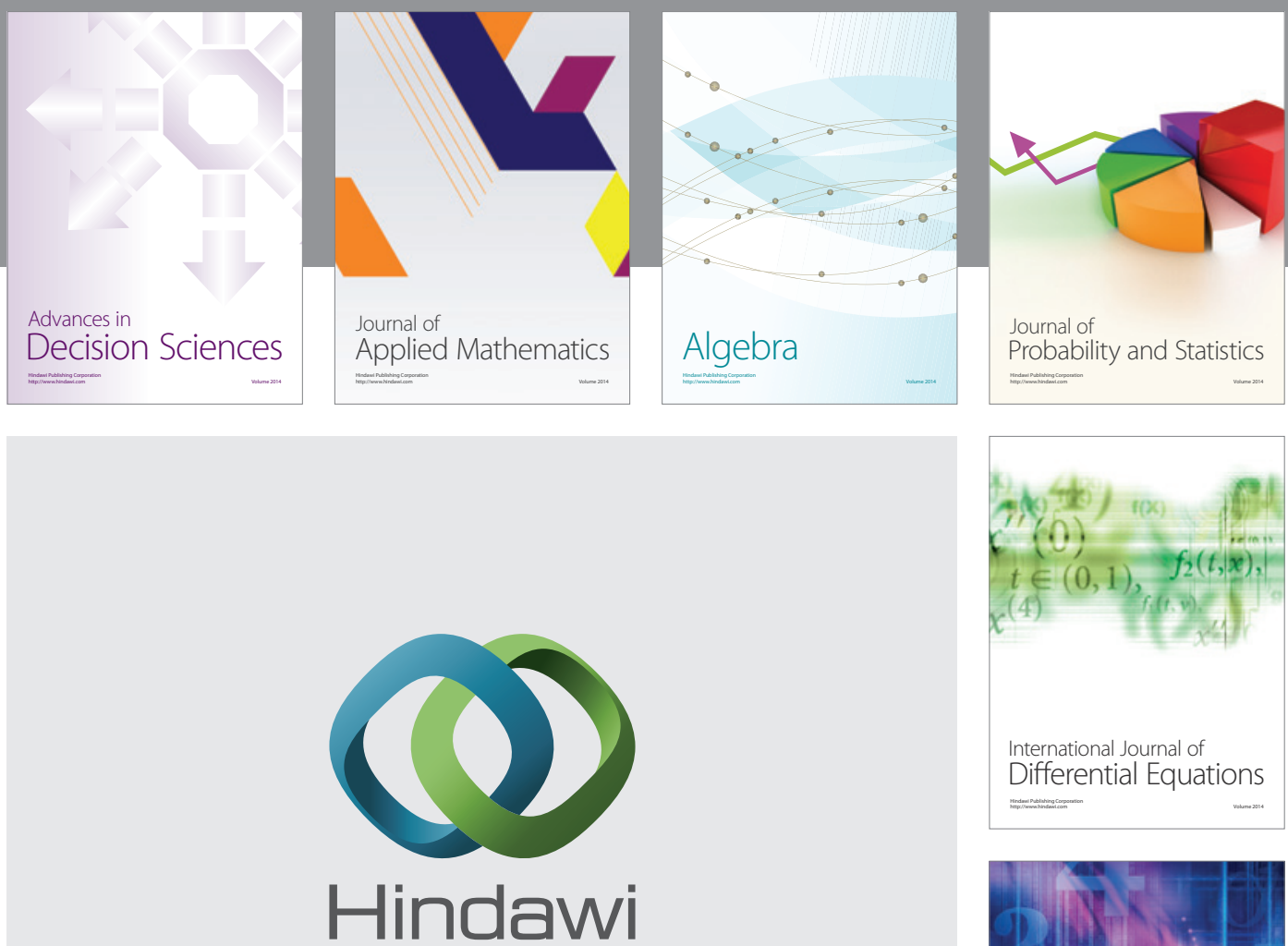

Submit your manuscripts at http://www.hindawi.com
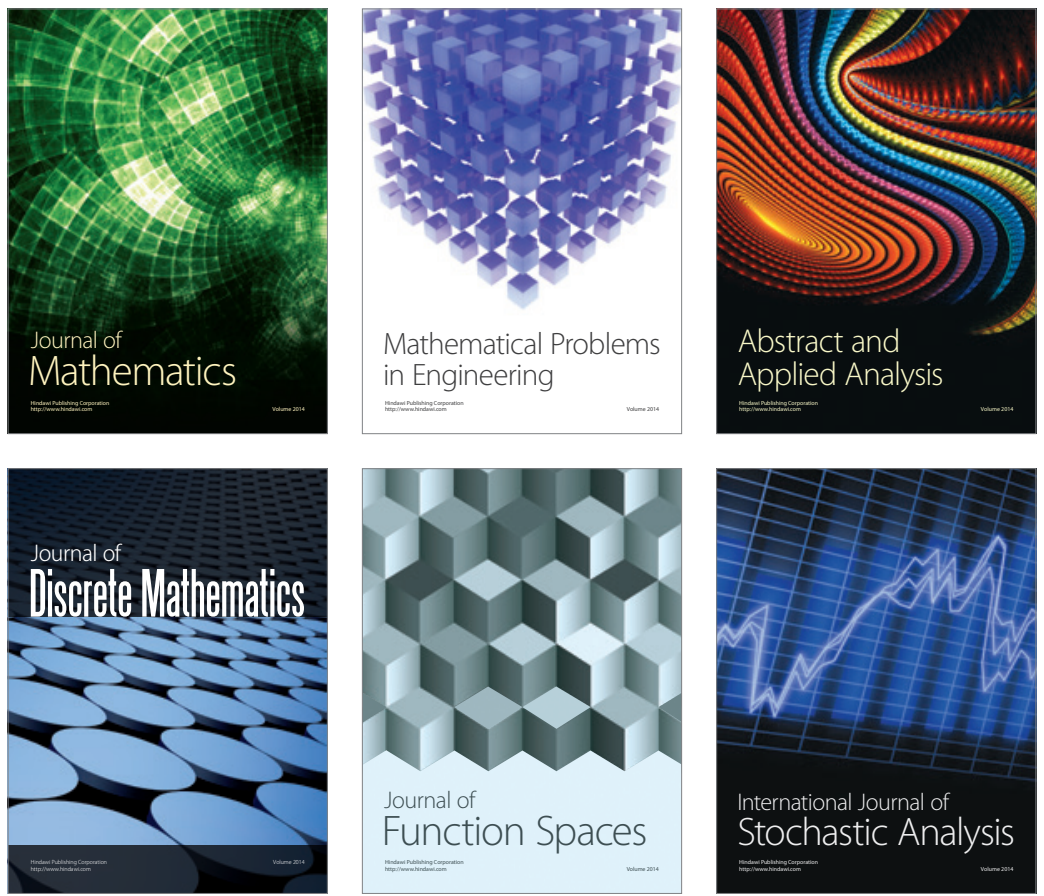

Journal of

Function Spaces

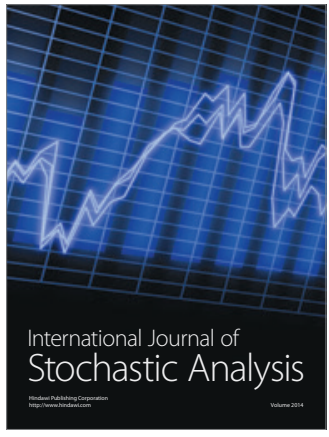

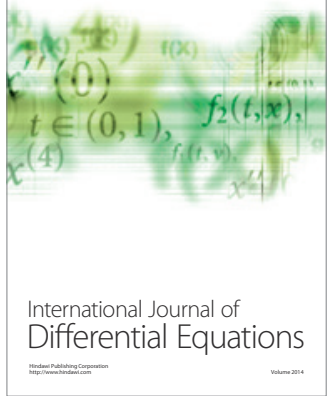
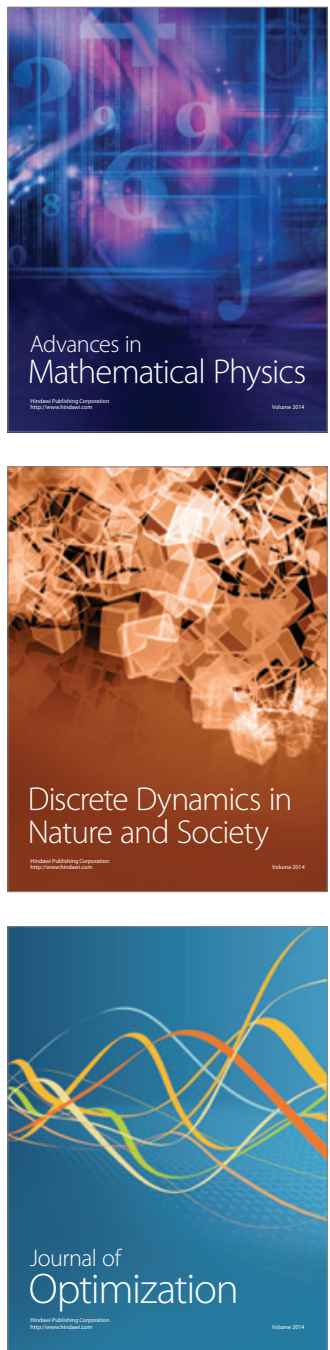